\title{
Baltasar Gracián: El concepto de interés propio como guía de la acción humana
}

\author{
ViCTORIANo MARTín MARTín a , NiEVES SAN EMETERIO MARTín ${ }^{\text {a }}$ \\ a Universidad Rey Juan Carlos, Facultad de Ciencias Jurídicas y Sociales, Paseo de los Artilleros, \\ s/n,28032 Madrid,España.E-mail: victoriano.martin@urjc.es, nieves.sanemeterio@urjc.es
}

\section{RESUMEN}

La obra de Baltasar Gracián, uno de grandes autores del siglo de oro español, ha interesado a filólogos, a filósofos morales y a teóricos políticos pero ha suscitado escasa atención a los economistas. Este papel indaga en la obra de este gran autor de barroco para resaltar el análisis de la naturaleza humana que se extrae de su obra, una noción de hombre muy similar a la de otros coetáneos españoles y que posee muchos de los atributos del homo oeconomicus, esa abstracción del hombre que iban a utilizar más tarde los economistas.

Palabras clave: Baltasar Gracián, homo oeconomicus.

\section{Baltasar Gracián: The Concept of Self- Interest as a Motive for Human Action}

\begin{abstract}
The work of Baltasar Gracián, one of the great writers of the Spanish Golden Age, has been interesting for philologists, moral philosophers and political theorists but it has hardly been relevant for economists. This paper explores the writings of this great author of the baroque period in order to emphasize the analysis of human nature derived from his work. Gracián suggested a very similar notion to that used by other Spanish contemporaries: one which possessed a great number of the qualities of the homo oeconomicus, an abstract conception of the human being which most of the economists will subsequently embrace.
\end{abstract}

Keywords: Baltasar Gracián, homo oeconomicus.

Clasificación JEL: B11, Z11

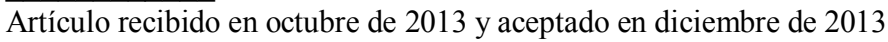

Artículo disponible en versión electrónica en la página www.revista-eea.net, ref. ə-32120 


\section{INTRODUCCIÓN}

Baltasar Gracián (1601-1658) pertenece al nutrido grupo de escritores del Siglos de Oro Español y su obra ha sido objeto de numerosos estudios en el campo de la filología. Su peculiar estilo ha sido bautizado como "conceptismo": una forma de escritura que se caracteriza por la concisión de la expresión y la intensidad semántica de las palabras. En esta corriente literaria prolifera el uso de palabras con varios significados y la utilización de la elipsis es un recurso muy empleado. Por todo ello la comprensión en muchas ocasiones se dificulta premeditadamente. El mismo Gracián señalaba, "la verdad, cuanto más dificultosa, es más agradable, y el conocimiento que cuesta es más estimado. Son noticias pleiteadas, que se consiguen con más curiosidad, y se logran con mayor fruición que las pacíficas" [Gracián, (1969), Discurso VII, 99]. Pero más allá del aspecto puramente formal de la escritura gracianesca la influencia de este autor hace tiempo que trascendió el campo puramente literario. Son abundantes los estudios de Gracián que se han llevado a cabo en el campo de la filosofía moral y la teoría política ${ }^{1}$. En este último campo se le asocia habitualmente con Hobbes porque como él tomó prestado de Plauto el famoso "homo homini lupus" el mismo año que lo hizo el autor del Leviatán.

En la esfera estrictamente económica, su libro, El arte de la prudencia, es utilizado con frecuencia en las escuelas de negocios como ejemplo de la actitud que debe tener un ejecutivo si desea prosperar en su empresa. Pero son muy escasos los estudios rigurosos de su obra realizados desde la perspectiva económica. Es destacable en este sentido el análisis llevado a cabo por Emilio Blanco desde el ámbito de la filología. En él interpreta el significado de los términos económicos que emplea Gracián como crédito, valor, caudal o estimación ${ }^{2}$ [Blanco, (2010)]. El estudio de García Durán merece más nuestra atención por cuanto realiza una interpretación de la obra de Gracián desde el punto de vista de la teoría economía contemporánea. De este modo extrae una teoría de la demanda, de la oferta, del capital humano, de la inversión, del ahorro e incluso llega hacer una asociación de Gracián con el Teorema de imposibilidad de Arrow [García Durán, (1995), 110]. Sin embargo, el propósito de este papel es otro. Tratamos de reivindicar para Gracián un puesto de honor entre el conjunto de autores que en el siglo XVII llegan a transformar de forma generalizada el concepto de interés propio hasta convertirlo en el elemento explicativo preponderante del comportamiento humano. El recorrido además de ser muy largo, ni tan siquiera fue único, pero el resultado fue el mismo. Al final del camino nos

\footnotetext{
${ }^{1}$ Elena Catarino ha recogido la amplia bibliografía dedicada a Baltasar Gracián en las últimas décadas en los diferentes campos mencionados (Cantarino, 1993b y 1997).

${ }^{2}$ Es especialmente interesante el estudio que realiza sobre la teoría de valor de corte subjetivo que se puede extraer de la obra de Gracián [Blanco, 2010, pp.151-157].
} 
encontramos con un concepto pesimista de la naturaleza humana como resultado de un análisis de los hombres tal como son en la realidad dejando de lado el deber ser. Gracián no parece que confiara mucho en las bondades innatas del género humano; aún así, en sus obras como El arte de la Prudencia o El Criticón, dibujó a un ser humano eminentemente práctico en el que su interés personal puede sobreponerse y triunfar en un mundo hostil. En la lectura de Gracián resuenan las ideas de Maquiavelo, de Hobbes, o de Hume y por ello es pertinente recuperarlo para estudiar las bases intelectuales del capitalismo moderno.

Comenzamos este papel resaltando la importancia de este programa de investigación en la ciencia económica. Veremos cómo en las últimas décadas son numerosos los trabajos de investigación en economía que rastrean el origen intelectual del homo oeconomicus en la literatura del siglo XVII y XVIII. En segundo lugar, destacamos algunos de los autores españoles del siglo XVII que están dentro de esta tradición. Aquí nos referimos de forma somera a los jesuitas Luis de Molina y Francisco Suárez y a otros autores que fuera de la teología describieron los rasgos del ser humano de forma muy similar a Baltasar Gracián. Veremos, por tanto, que el trabajo de Gracián no fue único en la España del XVII sino que estaba integrado dentro de una tradición dentro y fuera del pensamiento escolástico. Tras esta introducción repasaremos las obras de Gracián extrayendo de ellas aquellos aspectos que las monografías económicas han considerado más significativos para la construcción intelectual de homo eoconomicus. Por último, concluiremos con una valoración de la importancia de Baltasar Gracián en esta historia intelectual.

\section{INVESTIGACIÓN EN ECONOMÍA SOBRE EL ORIGEN INTELECTUAL DEL HOMO OECONOMICUS}

Durante el siglo XVII, tras un recorrido bastante azaroso a lo largo de la Edad Media y el Renacimiento, el concepto de "interés propio" como elemento explicativo preponderante del comportamiento humano se va a convertir en el axioma sobre el que se levantarán dos disciplinas nuevas: la Economía y la Política. Aquí hunde sus raíces el famoso homo oeconomicus, un concepto que lo economistas tomamos prestados de la filosofía política pero que ha sido un concepto tan fructífero que podemos decir que "el concepto de interés individual y la eficacia de incentivos son tan fundamentales para la microeconomía como las leyes de Newton para la física" [Quirk, (1979)].

Economistas e historiadores han dedicado sus investigaciones a indagar sobre el origen intelectual de este homo oeconomicus. Albert O. Hirschman, en su libro Las pasiones y los intereses (1977), es uno de estos economistas que rastrean el origen intelectual de esta criatura. En un intento de "arrojar luz sobre las consecuencias políticas del crecimiento económico, y, quizá en mayor medida aún, sobre las correlaciones políticas del crecimiento económico tan frecuente- 
mente desastrosas" ha mostrado muchas conexiones esenciales entre el desarrollo del concepto moderno de "interés propio" y el progreso de la Filosofía Moral, de la Economía y de la Política en el siglo XVII. Hirschman ha indagado sobre aquellas conexiones en los siglos XVII y XVIII, pero también ha buscado la filiación de ideas en la Edad Feudal y el Renacimiento. En última instancia acepta el reto planteado por Weber de explicar "cómo se volvieron honorables las actividades comerciales, bancarias, y otras similares para obtener dinero, en algún momento de la época moderna tras haber sido condenadas o despreciadas con ambición, amor por el lucro, y avaricia durante los siglos anteriores" [Hirschman, (1977), pp.11 y 17].

Hirschman ha sintetizado muy bien este viaje en el mundo de las ideas, pero hubo algunos antecedentes. Una síntesis más apretada sobre la evolución de estas ideas fue publicada por J. A. W. Gunn en 1968 con el título "Interest will not lie": A Seventeenth-Century Political Maxim". Y con carácter más monográfico, Mannerl O. Keohane publicó en 1974 "Nonconformist Absolutisme en Louis XIV`s France: Pierre Nicole and Denis Veiras". En 2003 y, según manifiesta el propio autor, inspirado en la autoridad de Hirschman, Pierre Force publicó Self-Interest before Adam Smith A Genealogy of Economic Science. Se trata esta última de una obra fascinante para quienes, como nosotros, están interesados en la antropología del homo oeconomicus.

Pues bien, como hemos adelantado, el camino fue largo pero existieron diferentes senderos que se deducen con claridad de las monografías citadas. En primer lugar, aunque tal vez existan algunos antecedentes, hay que referirse al capítulo XV de El príncipe de Maquiavelo. En él se desprende un análisis de la naturaleza humana partiendo de la contemplación de los individuos tal y como son en la realidad dejando de lado el deber ser. El enfoque de Maquiavelo sentaría el inicio de la transformación de la historia que nos estamos refiriendo que contaría con Hobbes como principal exponente en diseccionar las partes más abominables del ser humano con el fin constructivo de crear una sociedad civil.

\section{LAS IDEAS SOBRE EL "PROPIO INTERÉS" EN EL SIGLO XVII ESPAÑOL}

Como es sabido los escolásticos españoles del siglo XVI y XVII han resultado ser una fuente muy fructífera para la investigación en economía. No sólo se pueden extraer de sus tratados importantes aportaciones en el terreno de la teoría monetaria sino que, a la luz de la Nueva Economía Institucional, se revaloriza hoy más que nunca su análisis del Estado y su defensa de la propiedad privada [San Emeterio Martín, (2005), Martín Martín, (2011)].

Conviene indagar brevemente en la obra de los escolásticos para extraer las diferencias y similitudes con la descripción del hombre de Gracián. En la obra de autores como los jesuitas Francisco Suárez (1548-1616) o Luis de Molina 
(1535-1600) podemos encontrar una descripción clara de la naturaleza humana. Sin embargo es necesario hacer una puntualización. Ellos, como la mayoría de autores escolásticos, contemplan dos escenarios: un estado de naturaleza anterior al pecado original en el que el hombre disfruta de libertad, igualdad e independencia; y un estado de naturaleza caída. Es en este escenario donde el hombre se ve impelido a entregar su libertad natural a favor de los lazos establecidos de las leyes humana y civil. La descripción del hombre en ese estado es bastante perturbadora:

"Después del pecado (...) los hombre se han vuelto más perezosos y débiles para el trabajo, estando llenos de afectos depravados y de pasiones (...). Supuesta la malicia y la imbecilidad de los hombres subsiguiente a la pérdida de la justicia original" se hace necesario vivir "en un Estado integro y perfecto para que pueda conservarse entre los hombres la paz, la seguridad y la justicia. Ya que (...) con el poder del Estado cada uno se halla mejor defendido contra las injurias de los demás y son más fácilmente perseguidos y castigados los malhechores y facinerosos (...) y como quiera que las pasiones del hombre después del pecado están inclinadas al mal y en la juventud demuestra la experiencia que casi todos se dejan dominar por sus depravados instintos, es evidente que si vivieran fuera de la comunidad política, sin que hubiera un poder público superior que los pudiera coercer y reprimir, serían innumerables las matanzas, revoluciones, rapiñas, hurtos, dolos y fraudes, opresión de los débiles por los poderosos, y sería mucho peor la condición y miseria del género humano" [Molina, (1941), Vol. I, Disputa XX. 5, pp. 350-351, y Disputa XXII, 6, pp. 379-380].

Para Suárez, como para Molina, el interés propio también conduce al hombre a renunciar a su libertad natural a favor de un poder público:

"Cada uno de los miembros particulares mira por su conveniencias particular, la cual muchas veces es contraria al bien común, y a veces hay muchas cosas que son necesarias para el bien común, las cuales no son tan necesarias para cada uno de los particulares, y aunque a veces sean necesarias no se procuran porque sean de interés común sino porque son de interés particular, luego en una comunidad es necesario el poder público al cual por oficio corresponda buscar y procurar el bien común" [Suárez, (1612), (1967), Libro III, iii, 5, p.199)].

Como vemos en estas citas, el "interés particular" domina al hombre en el estado de naturaleza caída. Las similitudes con la obra de Hobbes son claras. Para los jesuitas españoles como para el autor inglés, el Estado surge para aliviar al hombre de la situación de inseguridad e injusticia del estado presocial.

No nos consta que Gracián conociera los escritos Francisco Suárez y Luis de Molina, especialmente su teoría de la ley civil y en definitiva de la autoridad política edificada sobre la base de los intereses egoístas de los individuos, pero pudo aprender estas ideas en sus cursos de teología en la Universidad de Zaragoza ya que es muy probable que esta fuera doctrina común en los cursos controlados por los jesuitas. Si bien es cierto que existen diferencias. Tanto Suárez 
como Molina escribieron dentro de los cánones de la moral cristiana. El discurso de Gracián es totalmente profano y no hace distinción ninguna en la naturaleza del hombre, antes o después del pecado original. Además la concepción de Gracián de la naturaleza humana es mucho más negativa y sombría que la de Suárez o Molina aunque homologable a la defendida en el siglo XVII español por filósofos políticos y economistas.

Tal vez por la secularización en su discurso es probable que la obra de Gracián comparta más puntos en común con estos autores. Parece conveniente reproducir aquí un texto de Diego de Saavedra Fajardo (1584-1648) no sólo por su claridad sino también por la concepción de la naturaleza humana tan similar a la de Gracián. Así sostiene Saavedra Fajardo,

"Estos engaños y artes políticas no se pueden conocer si no se conoce bien la naturaleza del hombre, cuyo conocimiento es precisamente necesario al que gobierna para saber regille y guardarse dél; porque, si bien es invención de los hombres el principado, en ellos peligra, y ningún enemigo mayor del hombre que el hombre. No comete el águila al águila ni un áspid a otro áspid, y el hombre siempre maquina contra su misma especie.(...) Por eso señalaremos aqui al príncipe una breve descripción de la naturaleza humana cuando se deja llevar de la malicia. Es pues el hombre el más inconstante de los animales, a sí y a ellos dañoso. Con la Edad, la fortuna, el interés y la pasión se va mudando. No cambia más semblantes el mar que su condición. Con especie de bien yerra, y con amor propio persevera" [Saavedra Fajardo, [1640] (1947), p115].

No es menos sombría la concepción que como economista tiene Miguel Álvarez Ossorio y Redín, quien se lamenta con dolor que

"el hombre solicite la ruina del hombre. Quien se pudo librar de un enemigo de tantas fuerzas, tan poderoso y astuto, como el propio hombre, enemigo declarado suyo (...).De modo que la guerra, que el hombre tiene pregonada contra el hombre, no procede de la naturaleza, sí de la malicia. Ésta ha llegado a la mayor grandeza, que jamás se ha visto; y los hombres por ella se gobiernan, y hacen tantos desaciertos, persiguiendo sus semejantes, como lobos y tigres ferocísimos" [Álvarez Ossoio y Redin, [1775] (2009), p.9].

Como veremos, la concepción de la naturaleza humana de Gracián guarda muchas semejanzas no solamente con la de sus superiores en la Compañía de Jesús, sino también con la de sus contemporáneos del siglo XVII. Ahora bien, esta idea no es exclusiva de Baltasar Gracián. Estaba bastante extendida por toda Europa. Acabamos de ver cómo esta descripción de la naturaleza humana era común en los filósofos políticos españoles, como también aparece en la obra de Samuel Pufendorf (1632-1694) cuando utiliza la misma comparación de los individuos a las fieras al referirse a la maldad inherente en el género humano [Pufendorf, (1990) [1682], p.162]. Con todo existen discrepancias. La diferencia está en el carácter finalista de su análisis. Más adelante veremos que Gracián no está preocupado ni por la organización política ni por la estructura de incentivos de la economía. Su problema es el individuo y su objetivo la promoción y el 
triunfo del mismo en un mundo sembrado de peligros por los propios congéneres a quienes considera más peligrosos que a las propias fieras.

\section{LA CONCEPCIÓN DE LA NATURALEZA HUMANA EN GRACIÁN}

Baltasar Gracián, jesuita como lo fueron Molina y Suárez, heredó de ellos una raíz individualista en la que iba a profundizar más allá de sus hermanos de religión. Sin embargo, y a diferencia de ellos, toda su obra, excepto un único libro, El Comulgatorio, es totalmente profana. No le fue fácil compaginar su profesión en la cátedra de Sagrada Escritura con la publicación de algunas de sus obras más radicales, como en el caso de El Criticón. De hecho Gracián utilizó el pseudónimo de Lorenzo Gracián en la mayoría de ellas y nunca llegó a solicitar la debida censura y licencia de un superior antes de llevarlas a la imprenta. Finalmente su temor se vio confirmado cuando sus superiores, advertidos de la verdadera autoría, le prohibieron expresamente imprimir una vez publicada la segunda parte de El Criticón en 1653. Él desobedeció y escribió una tercera parte que le valió una represión de ayuno a pan y agua y la privación de su cátedra durante seis meses. Este castigo hizo que Gracián se planteara incluso el abandono de la orden, pero nunca llegó a producirse [Romera-Navarro, (1938), 11-15].

Las dos obras de Gracián en las que podemos descubrir la descripción del hombre en los aspectos que más tarde iba a tomar prestado la ciencia económica son: El Criticón (1938) [1651-1657] y el Oráculo Manual y Arte de la Prudencia (1993) [1647] $]^{4}$. Nos referiremos a aspectos tales como la percepción del hombre como es en realidad y no como debiera, sus instintos egoístas, la descripción de Gracián del estado de naturaleza y la interpretación de la sociedad a la luz de tales postulados. Al hilo de estos aspectos elaboraremos las comparaciones con autores como Maquiavelo, Hobbes o Hume que, como es sabido, pertenecen al grupo de autores que perfilaron los atributos del homo oeconomicus.

\subsection{El hombre tal y como es}

Un paso decisivo en el proceso de transformación del concepto de hombre en los siglos que precedieron al triunfo del sistema capitalista fue el estudio de

\footnotetext{
${ }^{3}$ Utilizamos la edición crítica de Manuel Romera-Navarro (1938), en el castellano original. En adelante $\mathrm{C}$ en el texto.

${ }^{4}$ Aunque la edición utilizada lleva el Título de El Arte de la Prudencia (1993), se reconoce en el prólogo de la edición que el título correcto y completo es el de Oráculo Manual y Arte de la prudencia, por ello hemos preferido utilizar el acróstico OM en adelante en el texto. Las citas incorporan una primera cifra que hace referencia al número del aforismo, la segunda se refiere a la página, como es habitual.
} 
los individuos con un enfoque científico y positivo. Maquiavelo comenzó este viaje que fue secundado por Hobbes, Spinoza y Vico. Todos ellos separaron el mundo real de la moral de forma que, como decía Spinoza, era necesario "considerar las acciones y los apetitos humanos del mismo modo que se estuviera considerando líneas, planos y cuerpos" [Hirschman, (1977), 37-38].

Esta misma concepción del hombre la encontramos en la obra de Gracián. En él existe una perfecta delimitación entre lo humano y lo divino; entre lo que es necesario para triunfar en la vida y aquello que deberíamos hacer para ganar el cielo. En una de las sentencias del Oráculo Manual expone esta clara distinción: "Hay que usar los medios humanos como si los divinos no existieran, y los divinos como si no existieran los humanos" (OM, 251, 144). Una distinción con ecos de la famosa frase que Hugo Grocio incorporó en los prolegómenos de De Iuri Belli ac Pacis, en 1625, en donde daba validez a las leyes naturales aunque no existiera Dios [Grocio, (1987), 36]. Como sucede con Grocio y también con Gracián, tales distinciones son fruto del proceso de secularización en los planteamientos intelectuales y de la escisión abierta entre la esfera de lo humano y lo estrictamente religioso que se estaba produciendo ya en el siglo XVII.

El alejamiento de Gracián de los planteamientos religiosos se muestra sin ambages a la hora de dictar los aforismos de su Oráculo Manual, unas sentencias en las que aprueba conductas claramente contrarias a la moral cristiana como el aprovechamiento del prójimo $(144,84)$; las concesiones a la hipocresía y a la mentira $(130,75 ; 181,106 ; 243,140)$, al egoísmo $(189,111)$ o simple indiferencia ante la adversidad del desgraciado $(163,96)$. El ser humano que Gracián describe es uno eminentemente práctico que utiliza todas las armas a su alcance para conseguir sus objetivos, por ello no duda en recomendar estos comportamientos en cierto modo desviados de la moral cristiana. Para José Antonio Maravall, que estudió detenidamente este aspecto, Gracián construye su propia "moral en el plano de la mundanidad, sobre la mera experiencia de lo humano" [Maravall, (2001), 313]. Esta mundanidad de la que habla Maravall lleva a que el hombre que Gracián describe realice todo tipo de tretas para conseguir su provecho propio.

\subsection{El interés propio como guía del comportamiento}

Como señalan las monografías antes citadas que rastrean el origen intelectual del homo oeconomicus, en el transcurso de la Edad Moderna se produjo un reconocimiento gradual del interés propio como un motivo dominante del comportamiento humano, capaz de dotar de una base realista a un orden social. Estos autores reconocen a Maquiavelo como el primero en atribuir al interés un potencial constructivo.

Los vínculos que existen en Gracián son bastante claros. La lectura del Oráculo Manual desprende un importante aroma a Maquiavelo. Sin embargo, 
Gracián no sólo dice de Maquiavelo que es un falso político que "da a beber sus falsos aforismos a los ignorantes", sino que añade que bien examinados "no son otro que una confitada inmundicia de vicios y pecados: razones no de Estado, sino de Establo" (C, I, vii, 236). Es posible que esta crítica fuera causada por el hecho de que la obra de Maquiavelo estuviera incluida en el índice de libros prohibidos desde finales del siglo XVI y que Gracián, como otros tratadistas de la época, expresaran un desacuerdo común a su doctrina [Cantarino, (1993 a), 195]. Sin embargo, Maravall expone una razón de contenido que puede explicar este distanciamiento entre Gracián y Maquiavelo, una razón que de ser cierta conferiría a Gracián un mayor sesgo de modernidad. Gracián nunca define "la razón de Estado", pero sí advierte al lector en las primeras palabras de su obra El Héroe que él pretende dar "una razón de estado de ti mismo". A Diferencia de Maquiavelo, que quiere establecer principios que haga que el príncipe mantenga y acreciente su poder, Gracián, por su parte, cuando habla de razón de Estado, quiere decir "que cada uno es como un Estado, por tanto independiente, cerrado en sí y concurrente con los demás que en sí mismos fundan un orden de conducta, es decir, que sacan de sí el principio de este orden, el cual no es otro que el propio interés" [Maravall, (2001), 333].

Gracián no es un preceptista que establezca el modelo según el cual ha de conducirse el distinguido, el que pertenece a un grupo social establecido, antes bien, muy al contrario, "supone que ha de ser la aceptación de su modelo la que permita a alguien convertirse en el nuevo tipo de distinguido" [Maravall, (2002), 139-140]. Su personaje ejemplar, ese que sigue fielmente sus recomendaciones es simplemente el "hombre", un individuo cualquiera que por propia conveniencia desea prosperar en la sociedad.

Este impulso por mejorar su propia condición, como iba a decir Smith, es el motor que impulsa el comportamiento humano. Para lo cual Gracián utiliza todos los medios al alcance. Puede que sea necesario "empezar con la conveniencia ajena para salirse con la suya" (OM, 144, 85); o valerse de su privación pues "es una gran habilidad conservar la dependencia de los demás para conseguir lo que uno quiere" (OM, 189, 111). Algo muy parecido diría Adam Smith cuando señala lo provechoso que puede ser para uno mismo predisponer el egoísmo del prójimo a favor de uno mismo [Smith, [1776](1978), L.1, c.2, p. 96]. Para Gracián, vale todo tipo de argucias para obtener lo deseado, incluso sacar provecho del desprecio o de los enemigos (OM, 205, 118-9; 84, 49) ya que el prójimo actuará del mismo modo: "El prudente debe entender que nadie le busca a él, sino aprovecharse de él o de otro a través de él" (OM, 252, 145). Además el hombre siempre ha de tener algo que desear, "donde termina el deseo comienza el temor" (OM, 200,116). Cabría preguntarse si esta última idea es similar a la que resalta Hirschman en el pensamiento precapitalista cuando dice que allí la misma "insaciabilidad del hombre se convierte en virtud porque implica constancia" [Hirschman, (1977), 78]. Ciertamente Gracián no se limita 
a hablar del deseo ilimitado de "ganancia" como lo iban a hacer los precursores del pensamiento capitalista, siendo fieles, también habla del deseo de conocimiento, sin embargo, hay claras similitudes.

\subsection{El estado de naturaleza humana}

Este estricto pragmatismo que recomienda Gracián a todo hombre que quiera prosperar no se entiende completamente si no es dentro de una descripción del mundo. Igual que hiciera Hobbes en su Leviatán, Gracián indaga en la verdadera naturaleza humana. Es preciso "saber conocerse" señala en el Oráculo Manual $(89,53)$, "saber sabiéndose" es la primera norma de El Discreto [Gracián, (2004), 56] y es a través de esa introspección que cada uno se intenta abrir camino en un mundo plagado de maldad: "la vida del hombre es milicia contra la malicia del hombre" $(13,7)$. Esta visión pesimista del hombre y de su entorno enlaza nuevamente con los filósofos políticos del XVII y que, como antes hemos visto, también aparece en los teólogos españoles.

El retrato que hace del hombre Gracián poco se separa de la terrible descripción hobbesiana. Precisamente el mismo año que salía a la luz el Leviatán, 1651, aparecía la primera parte de El Criticón. En los dos aparece la famosa cita de Plauto, homo homini lupus est, que Gracián expresó del siguiente modo: "entre los hombres, cada uno es un lobo para el otro" (C, I, iv, 148). Sin embargo, poco después detalla una naturaleza humana que a su lado la de Hobbes, siendo terrible, podría considerarse inocente. El relato es tan sustancioso que merece su trascripción. Comienza Gracián señalando que "si los hombres no son fieras es porque son más fieros, que de su crueldad aprendieron muchas veces ellas". La providencia por ello les privó de las armas naturales de las fieras como se desarma a los sospechosos. Si no fuera así hubieran acabado con todo.

"Aunque no les faltan otras armas mucho más terribles y sangrientas que esas, porque tienen una lengua más afilada que las navajas de los leones, con que desgarran a las personas y despedazan las honras; tienen una mala intención más torcida que los cuernos de un toro y que hiere más a ciegas; tienen unas entrañas más dañadas que las víboras, un aliento más venenoso que el de los dragones, unos ojos envidiosos y malévolos más que los de un basilisco, unos dientes que clavan más que los colmillos de un xavalí y que los dientes de un perro, unas narices fisgonas (encubridoras de su irrisión) que exceden a las trompas de los elefantes. De modo que solo el hombre tiene juntas todas las armas ofensivas que se hallan repartidas entre las fieras, y assí el ofende más que ellas".

Entre las fieras, continúa Gracián, solo existe el peligro de perder la vida, "pero entre los hombres ay mucho más y mayores: ya de perder la honra, la paz, la hacienda, el contento, la felicidad, la conciencia y aun el alma. ;Qué de engaños, qué de enredos, traiciones, hurtos, homicidios, adulterios, envidias, inju- 
rias, detracciones y falsedades que experimentarás entre ellos! Todo lo cual no se halla ni se conoce entre las fieras" (C, I, iv, 150-2).

De esta terrible descripción de la naturaleza humana no es de extrañar que -como hemos visto- para prosperar en esa perversa jungla, Gracián aconsejara cualquier tipo de artimañas: engaños, medias mentiras, hipocresía, manipulaciones e indiferencia. En este sentido Gracián, como apuntaba Maravall, crea una "moral mundana", construida a partir de la misma naturaleza humana donde las cuestiones religiosas no entran en consideración $(2001,313)$.

Creemos que la cita anterior es suficiente para vincular a Gracián dentro de las corrientes de filósofos políticos del setecientos que, como en el caso de Hobbes, desentrañaron lo que según ellos era la esencia misma del hombre. Pero para ser intelectualmente honestos, hemos de decir que en muchos aspectos El Criticón y El Leviatán no son equiparables. Gracián elabora una moral, pero no da justificación alguna al poder político. Para Hobbes la descripción de la naturaleza humana le lleva a la necesidad de construir un poder que garantice la paz entre los hombres para que dejen de vivir bajo la amenaza continua de una guerra perpetua [Hobbes, (1993), XVII]. En Hobbes se enfrentan dos pasiones, y una, el deseo de supervivencia, reprime a la otra; por eso los hombres se someten voluntariamente al pacto que da origen al Estado. Lo mismo podemos decir de los jesuitas Luis de Molina y Francisco Suárez. Ambos dan una explicación del poder político pues la maldad natural del hombre ha de reprimirse por la autoridad para garantizar la paz y la consecución del bien común. En Gracián no hay nada parecido, su descripción de la naturaleza humana solo le lleva a formular un manual de supervivencia que le ayude a su hombre "prudente" a superar las adversidades y a sacar provecho de este mundo hostil.

\subsection{El individuo como mónada social}

Es difícil efectivamente equiparar a Gracián con Hobbes, o tan siquiera con sus hermanos de religión Suárez o Molina si nos fijamos en la teoría política en sentido estricto. Pero no lo es tanto si nos detenemos en otro aspecto: el individualismo metodológico. Hobbes no sólo resulta de gran relevancia por ser uno de los primeros filósofos políticos que elaboraron una teoría política moderna sino porque la construyó sobre supuestos de igualdad física y mental de todos los individuos: lo que Schumpeter ha denominado "igualitarismo analítico" [Schumpeter, (1994): 161-2]. Las ciencias sociales -y por supuesto, la economía- iban a tomar esta misma idea como supuesto teórico de sus formulaciones.

Algo similar podemos encontrar en Gracián. Su descripción de los hombres no depende del estamento al que pertenezca, ni del lugar que ocupe en la pirámide social, el hombre es el mismo en todas partes. Sus atributos y bagaje son comunes a todos ellos. Su hombre nace cual tabla rasa, "sin género alguno de conocimiento", "a oscuras llega, y aun a ciegas, quien comienza a vivir, sin 
advertir que vive y sin saber qué es vivir" (C, I, V, 166). Y, tan igual es a otro hombre, que se reconoce a sí mismo por primera vez cuando ve a otro hombre, "tú eres el primer hombre que hasta oy he visto, y en ti me hallo retratado más al vivo que los muchos cristales de una fuente que mi curiosidad solicitava" (C, $\mathrm{I}, \mathrm{i}, 111)$. A partir de este origen común, el ser humano se va puliendo a través de la educación, "un hombre sin conocimiento es un mundo a oscuras" (OM, 4, 2). Y alcanza su perfección mediante la libertad de elección; "no hay perfección donde no hay elección. Ella tiene dos ventajas: poder elegir y elegir bien", señala en El Discreto (2004, X, 110) y en El Oráculo Manual (51, 30); la elección -dice en otro lugar- "es uno de los más importantes favores de la naturaleza" (2004, X, 105).

La sociedad parte de este hombre, de naturaleza idéntica; en palabras de Maravall, los hombres son como "mónadas sociales", unidades autónomas en la construcción de la sociedad $(2001,333)$. No hay vínculos entre ellos, ni objetivos comunes más allá del que tiene cada uno por sobrellevar su simple existencia. Una existencia en un mundo que de haberse conocido antes "ninguno quisiera entrar" (C, I, V, 166).

Si Gracián poseía este estricto individualismo y no hay indicio alguno de colectivismo en toda su obra, ¿qué habría de pensar de esa "razón de Estado" que esgrimían los arbitristas y los economistas políticos contemporáneos? En su crítica a Maquiavelo -como vimos- le ridiculizaba hablando de "razón de establo". En otro lugar dice abiertamente del arbitrismo: "desdichados arbitristas, inventores de felicidades agenas (...), discurriendo trazas para que los otros coman quando ellos más ayunan, todo embeleco, devaneo de cabeza, necedad y quimera". Y de los "caprichosos políticos" señala: "amigos de peligrosas novedades, inventores de sutilezas mal fundadas, trastornándolo todo, no sólo no adquiriendo de nuevo ni conservando lo viejo, pero perdiendo cuanto ay, dando al traste con el mundo, y aun con dos, todo perdición y quimera" (C, II, iii, 856). Lo anterior parece demostrar que el individualismo de Gracián mantiene una coherencia con su expreso rechazo a los proyectistas sociales de la época.

Otra faceta de ese individualismo metodológico de Gracián tiene que ver con la perspectiva antropocéntrica del mundo. Erige al hombre, al mismo tiempo que en objeto de estudio, en el baremo del orbe que le rodea. De sus manos y de sus dedos proceden "la cuenta, el peso y la medida. En sus diez dedos está el principio y fundamento del número; todas las naciones cuentan hasta diez, y de aí suben multiplicando. Las medidas todas están en sus dedos, palmo, codo y brazada. Hasta el peso está seguro en la fidelidad de su tiento, sospesando y tanteando" (C, I, ix, 281).

Por último, aunque tal vez lo digamos con cautela, Gracián adelanta otro aspecto relevante en la búsqueda de las raíces intelectuales del sistema capitalista: la predictibilidad de comportamiento del hombre. Justo porque la naturaleza 
humana es común a todos los individuos, es posible, a través de la razón, extraer unas reglas de comportamiento: "para saber y poder vivir es esencial el método", dice en el Oráculo Manual $(249,144)$. Tanto es así que incluso se podrá penetrar en lo venidero. En la rueda del tiempo -dice- "no ay cosa más fácil que saber lo venidero. (...) porque has de saber que lo mismo que fue, esso es y esso será sin discrepar un átomo" (C, III, x, 304-5). Algo similar iba a decir David Hume casi un siglo más tarde, en su Tratado de la naturaleza humana, donde expresaba la idea de que "el futuro es semejante al pasado", pues de la experiencia podemos extraer "razones que nos lleven a hacer del pasado un criterio para el futuro" [Hume, (1998), 210].

\section{CONCLUSIONES}

De todo lo dicho creemos que hay indicios suficientes para que Baltasar ocupe un sitio dentro de la historia del pensamiento económico. Hemos visto que existe una secularización clara en su obra. No hay en ella referencias sobre cómo ha de comportarse el hombre para salvar su alma; el hombre de Gracián puede disfrutar de la gloria, pero de una gloria no en el paraíso celestial sino en un mundo de aspecto terrible. Sólo hay que seguir sus consejos para que, guiado por sus pasiones, el hombre consiga mejorar, fortalecer y levantar su posición ante los demás. Casi todo vale si se desea obtener esta gloria terrenal. Las mentiras, las manipulaciones, la falta de compasión por el prójimo, la hipocresía son argucias permitidas y también recomendadas por el código moral gracianesco. $\mathrm{Su}$ discurso nos recuerda en ocasiones a Smith cuando recomienda incitar el egoísmo del prójimo para obtener lo que se desea. Otras veces su discurso se asemeja más a Maquiavelo, aunque su individualismo es otro. No es al príncipe al que Gracián recomienda indagar en la verdadera naturaleza humana para perpetuarse en el poder; antes bien, sus consejos van dirigidos al mismo hombre que ha de vivir junto a seres mucho más peligrosos que las fieras y aún así quiere salir victorioso. Se trata de seguir lo que él llama "la razón de Estado de uno mismo". Por todo ello, no existen objetivos colectivos que perseguir o que inciten a la acción común; el hombre forma un microcosmos completo que le lleva a estructurar el mundo a su medida.

Muy cerca está este discurso del que Thomas Hobbes escribía en el Leviatán exactamente al mismo tiempo. La uniformidad y la deformidad de la naturaleza humana se encuentran reflejadas en los dos autores; el azar les lleva a utilizar incluso las mismas palabras para representar la crudeza del alma humana. En los dos se utiliza esa igualdad natural para construir su modelo de sociedad. Pero Hobbes dio un paso más que Gracián y por eso al autor inglés se le considera por justicia uno de los mayores filósofos políticos de todos los tiempos. Gracián se limita a construir una moral mundana, mientras que Hobbes articula 
toda una teoría del origen del Estado. En este sentido pensamos que Luis de Molina o Francisco Suárez se aproximan más al filósofo inglés que Gracián.

Si este papel pretendiera extraer las aportaciones de Gracián en teoría política no nos equivocaríamos si dijéramos que Hobbes y Gracián no están a la misma altura. Pero no ha sido éste el objetivo de este trabajo, hemos tratado de extraer los rasgos de la naturaleza humana de la obra de Gracián y cotejarlos con los atributos del homo oeconomicus. Pues bien, creemos que hay bastantes similitudes. Gracián construyó una moral mundana en donde la guía de acción para el hombre es su propio interés. Por ello, por su individualismo metodológico y por su perspectiva positiva en la que los hombres son analizados tal como son en la realidad, podemos concluir que Gracián es un autor a considerar en la historia del pensamiento económico.

Concluyamos. De lo anterior podríamos decir que Gracián, por méritos propios, podría ocupar un sitio en la reconstrucción de las bases intelectuales del capitalismo moderno. Sin embargo, es un autor que prácticamente no ha interesado a los economistas; aunque sí ha sido considerado por los estudiosos de la literatura, los filósofos morales y, en menor medida, por los teóricos políticos. Nosotros hemos querido resaltar aquí que si Maquiavelo, Hobbes o Hume son autores que la ciencia económica no debe olvidar dado que ellos esbozaron al homo oeconomicus, por el mismo motivo cabe estudiar a Baltasar Gracián. Sin embargo, hemos de hacer una advertencia sobre su lenguaje. La Literatura ha hecho concienzudos estudios sobre el estilo de Gracián y todos coinciden en la dificultad de entendimiento. Como dijimos en la introducción, la utilización de la metáfora, la elipsis, la abreviatura, el modo de apretar una expresión al máximo de laconismo, hace que su mensaje parezca codificado. Este conceptismo que Gracián busca premeditadamente puede haber provocado que la ciencia económica, de tradición anglosajona, no hubiera reparado en ella. De ser cierta esta explicación, su obra hubiera corrido la misma suerte de aquellos autores escolásticos del XVI y XVII que, a fuerza de conservar un método de escritura escolástico perdieron claridad y con ella la posibilidad de ser trasmitidos y entendidos fuera de nuestras fronteras.

\section{REFERENCIAS BIBLIOGRÁFICAS}

ÁLVAREZ OSSORIO y REDÍN, M., (2009) [1775]: Extensión política y Económica, En Pedro Rodríguez Campomanes, Apéndice a la Educación Popular, I, Instituto Feijoo de Estudios del Siglo XVIII, Oviedo. KRK Edicioness. 
BLANCO, E., (2010): “Del valor al crédito: Los conceptos económicos de Gracián”, en Sebastian Neumeister (Ed.): Los conceptos de Gracián, Berlín, Edition tranvía-Verlag Walter Frei, pp 147-169.

CANTARINO, E., (1993, a): "Gracián y la moral política: senequismo y tacitismo", Baltasar Gracián, Documentos A, n.5, febrero, Barcelona, Anthropos, pp.193-200.

CANTARINO, E., (1993, b): "Bibliografía de y sobre Baltasar Gracián" en Suplementos. Materiales de trabajo intelectual, Barcelona: Anthropos, pp.199-220.

CANTARINO, E., (1999): "Bibliografía sobre Baltasar Gracián (1996-1998)", Revista Contrastes, Málaga, Volumen IV.

FORCE, P. (2003): Self-Interest before Adam Smith. A Genealogy of Economic Science, Cambridge University Press.

GARCÍA DURÁN, J. A., (1995): “La cuenta y razón en economía de B. Gracián”, Economistas, n.65, pp.108-113.

GRACIÁN, B., (1938) [1651-57]: El Criticón, Edición crítica y comentada por M. Romera Navarro, Philadelphia, University of Pensilvania.

GRACIÁN, B., (1969) [1642]: Agudeza y arte de ingenio, ed. de E. Correa Calderón, Madrid, Castalia, 2 vols.

GRACIÁN, B., (1993) [1647]: El Arte de la Prudencia, Madrid, Temas de Hoy.

GRACIÁN, B., (2004) [1646]: El discreto y Oráculo Manual y Arte de la prudencia, Barcelona, Mondadori.

GROCIO, H., (1987) [1605] [1625]: Del Derecho de Presa, Del Derecho de la Paz y de la Guerra, Madrid, Centro de Estudios Constitucionales.

HIRSCHMAN, A. O.(1977): Las pasiones y los intereses, Barcelona, Península.

HOBBES, T., (1993) [1651]: Leviatán. La materia, forma y poder de un Estado eclesiástico y civil, Madrid, Alianza Editorial.

HUME, D., (1998). [1739-40]: Tratado de la naturaleza humana, Madrid, Tecnos.

GUNN, J. A. W., (1968): ""Interest Will Not Lie": A Seventeenth-Century Political Maxim": Journal of the History of Ideas, Vol. 29, No. 4, pp. 551-564.

KEOHANE, M. O. (1974): "Nonconformist Absolutisme en Louis XIV`s France: Pierre Nicole and Denis Veiras", Journal of the History of Ideas, Vol. 35, No 4. pp. 579-596.

MARAVALL, J. A., (2001): "Antropología y política en el pensamiento de Gracián" en Estudios de Historia del Pensamiento Español, III, Madrid, Ediciones Cultura Hispánica, AECl.

MARAVALL, J. A., (2002): La cultura del barroco, Barcelona, Ariel.

MARTÍN MARTÍN, V., (2011): "Teoría del Estado y derechos de propiedad en la Escolástica española del siglo XVI: un antecedente de la Nueva Economía Institucional", Revista del Instituto de Estudios Económicos, Número 2, pp. 81-110.

MOLINA, L. (1941): Los seis libros de la Justicia y el Derecho, Traducción, estudio preliminar y notas de Manuel Fraga Iribarne, Madrid, Universidad Complutense de Madrid, Facultad de Derecho.

PUFENDORF, S., (1990) [1682]: On The Duty of Man and Citizen, en J. B. Schneewind Ed.: Moral Philosophy from Montaigne to Kant. An Anthology, Cambridge, Cambridge University Press.

QUIRK, J. P., (1979): Microeconomía, Barcelona, Antoni Bosch. 
ROMERA NAVARRO, M., (1938): “Introducción”, El Criticón, Philadelphia, University of Pensilvania.

SAAVEDRA FAJARDO, D., (1941), Idea de un príncipe político cristiano, representado en cien empresas. En Obras, Biblioteca de Autores Españoles, Madrid, Atlas.

SAN EMETERIO MARTÍN, N., (2005): Sobre la propiedad. El concepto de propiedad en la Edad Moderna, Madrid, Tecnos.

SCHUMPETER, J. A., (1994): Historia del Análisis Económico, Barcelona, Ariel.

SMITH, A., (1988) [1776]: La Riqueza de las Naciones, Barcelona, Oikos-Tau.

SUÁREZ, F., (1967) [1612]: Tratado de las leyes y de Dios Legislador, en diez libros, Madrid: Instituto de Estudios Políticos. 